\title{
Immune response and pathophysiological features of Klebsiella pneumoniae liver abscesses in an animal model
}

\author{
Chang-Phone Fung ${ }^{1, *}$, Feng-Yee Chang ${ }^{2, *}$, Jung-Chung Lin ${ }^{2}$, Donald Ming-Tak Ho ${ }^{3}$, Chiung-Tong Chen ${ }^{4}$, \\ Jiun-Han Chen ${ }^{5}$, Kuo-Ming Yeh ${ }^{2}$ Te-Li Chen ${ }^{1}$, Yi-Tsung Lin ${ }^{1}$ and L Kristopher Siu ${ }^{6, *}$
}

Capsular serotypes $\mathrm{K} 1$ and $\mathrm{K} 2$, the rmpA gene (a regulator of the mucoid phenotype) and aerobactin from Klebsiella pneumoniae have been identified as the major virulence factors for pyogenic liver abscesses with high morbidity, mortality and severe complications. The pathological mechanisms remain unclear. In this study, we compared liver immune responses and pathological changes in response to different serotypes of $K$. pneumoniae infections. A mouse model was used to investigate cytokine and chemokine production, histopathology findings, phagocytic uptake and mortality induced by serotypes $\mathrm{K} 1\left(\mathrm{magA}^{+}, \mathrm{rmpA}^{+}\right.$, aerobactin $\left.{ }^{+}\right), \mathrm{K} 2\left(\mathrm{magA}^{-}, r m p A^{+}\right.$, aerobactin $\left.{ }^{+}\right), \mathrm{K} 62\left(\mathrm{magA}^{-}\right.$, $r m p A^{-}$, aerobactin $\left.{ }^{-}\right)$and an acapsulated isogenic $\mathrm{K} 1$ mutant $\left(\Delta \mathrm{K} 1, m a g A^{+}, r m p A^{+}\right.$, aerobactin $\left.{ }^{+}\right) . K$. pneumoniae serotypes $\mathrm{K} 1$ and $\mathrm{K} 2$ showed lower $50 \%$ lethal dose values and more phagocytic resistance to neutrophils than $\mathrm{K} 62$ and the $\Delta \mathrm{K} 1$ mutant. In sequential liver samples, viable bacteria counts increased $3 \mathrm{~h}$ to 3 days after low-dose inoculation $\left(<10^{1}\right.$ colony-forming unit (cfu)) with $\mathrm{K} 1$ and $\mathrm{K} 2$, while $\mathrm{K} 62$ and $\Delta \mathrm{K} 1$ cleared rapidly and became undetectable even with high-dose inoculation $\left(\sim 2.9 \times 10^{5} \mathrm{cfu}\right)$. Time-dependent increases in cytokines and chemokines, including tumor necrosis factor- $\alpha$, interleukin (IL)-1 $\beta$, IL-6, IL-10, keratinocyte-derived chemokines and macrophage inflammatory protein-2, were observed in the serum and liver tissue of $\mathrm{K} 1$ - and $\mathrm{K} 2$-infected mice, and severe disease progression manifesting as microabscesses was also identified. $\mathrm{K} 62$ and $\Delta \mathrm{K} 1$ inoculation did not result in similar immune responses and histological changes. These findings illustrate the critical role of phagocytic resistance against innate immunological defense mechanisms as well as its contribution to the development of liver abscesses.

Laboratory Investigation (2011) 91, 1029-1039; doi:10.1038/labinvest.2011.52; published online 4 April 2011

KEYWORDS: aerobactin; capsular serotypes; cytokine production; Klebsiella pneumoniae; pyogenic liver abscess; $r m p A$ gene

Klebsiella pneumoniae is the most common pathogen causing pyogenic liver abscess (PLA) in East and Southeast Asia. ${ }^{1-4}$ Its emergence in western countries has also been reported. ${ }^{5-7}$ Previous studies in Taiwan, Singapore and Korea found a high prevalence of the capsular polysaccharide (CPS) $\mathrm{K}$ antigen serotypes $\mathrm{K} 1(54.5-63.4 \%)$ and $\mathrm{K} 2(5-21.2 \%)$ of K. pneumoniae in liver abscess isolates. ${ }^{1,8-10}$ Apart from the capsular serotypes, other virulence determinants have also been reported for $K$. pneumoniae liver abscesses, including the presence of hypermucoviscosity, aerobactin, magA (mucoviscosity-associated gene $A$ ), rmpA (regulator of mucoid phenotype), $k f u$ (responsible for an iron uptake system) and allS (associated with allantoin metabolism) genes. ${ }^{11-13}$ A previous study showed that all of the K1 and K2 strains isolated from liver abscesses harbored the rmpA genes, and all $\mathrm{K} 1$ isolates carried magA, $k f u$ and alls genes. ${ }^{13} \mathrm{Al}-$ though a few $\mathrm{K} 1$ and $\mathrm{K} 2$ isolates were less virulent, they were non-mucoid, lacked the $\operatorname{rmp} A$ gene or aerobactin and were found only in urine and not in liver abscesses. ${ }^{13-16}$

The bacterial capsule has been identified as having an important role in neutrophil and macrophage phagocytosis of bacteria. In K. pneumoniae, $77 \mathrm{~K}$ antigen types of CPS have been identified to date. Only a few serotypes, specifically $\mathrm{K} 1$ and $\mathrm{K} 2$, are highly prevalent in community-acquired liver

\footnotetext{
${ }^{1}$ Division of Infectious Diseases, Department of Medicine, Taipei Veterans General Hospital and National Yang-Ming University, Taipei, Taiwan, ROC; ${ }^{2}$ Department of Internal Medicine, Tri-Service General Hospital, National Defense Medical Center, Taipei, Taiwan, ROC; ${ }^{3}$ Department of Pathology and Laboratory Medicine, Taipei Veterans General Hospital and National Yang-Ming University, Taipei, Taiwan, ROC; ${ }^{4}$ Division of Biotechnology and Pharmaceutical Research, National Health Research Institutes, Zhunan, Taiwan, ROC; ${ }^{5}$ Department of Medical Laboratory Science and Biotechnology, Yuanpei University, Hsinchu, Taiwan, ROC and ${ }^{6}$ Division of Infectious Diseases, National Health Research Institutes, Zhunan, Taiwan, ROC

Correspondence: Dr C-P Fung, MD, Division of Infectious Diseases, Department of Medicine, Taipei Veterans General Hospital, 201, Section 2, Shih-Pai Road, Taipei 11217, Taiwan, ROC or Dr LK Siu, PhD, Division of Infectious Diseases, National Health Research Institutes, Zhunan, Taiwan, ROC. E-mail: cpfung@vghtpe.gov.tw or Iksiu@nhri.org.tw

*This work was a collaboration between three principal investigators (C-PF, F-YC and LKS) who contributed equally to this project. 
abscesses with severe extrahepatic metastasis that includes septic endophthalmitis. ${ }^{1}$ Therefore, further investigation of the effects of these two specific serotypes on liver inflammation and innate immune responses is urgently required. In the present study, we used a mouse model to determine whether there is a correlation between liver inflammation and cytokine and chemokine responses with different capsule serotypes or with their capsule-deficient isogenic mutants.

\section{MATERIALS AND METHODS Microorganisms}

Four different bacterial strains, ie, serotypes $\mathrm{K} 1\left(\mathrm{mag} A^{+}\right.$, $r m p A^{+}$, aerobactin $\left.{ }^{+}\right), \mathrm{K} 2\left(m a g A^{-}, r m p A^{+}\right.$, aerobactin $\left.{ }^{+}\right)$, $\mathrm{K} 62$ (mag $^{-}, \operatorname{rmp} A^{-}$, aerobactin $\left.{ }^{-}\right)$and $\Delta \mathrm{K} 1{\left(m a g A^{+}\right.}^{+}$, $r m p A^{+}$, aerobactin ${ }^{+}$), were included in this study. K1 (STL43) and K2 K. pneumoniae strains were isolated from a patient with liver abscesses. The K62 strain was obtained from a urine sample from a non-liver abscess patient. $\Delta \mathrm{K} 1$ is a non-polar glycosyl transferase gene $(r f b P)$ mutant derived from an STL43 strain in our previous study that proved to be an acapsular and non-mucoid mutant. ${ }^{17}$ Gene clusters related to K1 capsule formation were sequenced and published in Genbank under accession number AY762939. ${ }^{18}$ Virulence-associated magA, rmpA and aerobactin were confirmed repeatedly with specific, previously described primer sets for PCR identification (magA forward, $5^{\prime}$-CGTGCTCTT TACATCATTGC- $3^{\prime}$, magA reverse, $5^{\prime}$-GCAATGGCCATTTG CGTTAC-3'; rmpA forward, 5'-ACTGGCTACCTCTGCTT CA-3', rmpA reverse, 5'-CTTGCATGAGCCATCTTTCA-3'; aerobactin forward, 5'-GCATAGGCGGATACGAACAT- $3^{\prime}$, aerobactin reverse, $5^{\prime}$-CACAGGGCAATTGCTTACCT- $\left.3^{\prime}\right) .{ }^{12,13}$

\section{Animals}

Specific pathogen-free 6- to 8-week-old male BALB/c mice were obtained from and housed at the National Defense Medical Center in Taipei, where they were provided with food and water ad libitum. The procedures were approved by the Ethics Committee and the Institutional Animal Care and Use Committee of the National Defense Medical Center in Taipei and the Institutional Review Board of Taipei Veterans General Hospital.

\section{Preparation of BALB/c Sera and Mouse Neutrophils}

$\mathrm{BALB} / \mathrm{c}$ serum was prepared following heart puncture after $\mathrm{CO}_{2}$ inhalation. Clotted blood was centrifuged at $1000 \mathrm{~g}$ for $20 \mathrm{~min}$ at $20^{\circ} \mathrm{C}$. The sera were pooled and aliquots were stored at $-70^{\circ} \mathrm{C}$ until use.

Neutrophils of $B A L B / c$ mice were prepared from the peritoneum as described previously. ${ }^{19}$ The cell concentration was adjusted to $1 \times 10^{7}$ cells $/ \mathrm{ml}$. The viability of the isolated neutrophils exceeded 95\%, as determined by trypan blue exclusion.

\section{Phagocytosis Assay}

The bacteria were labeled with fluorescein isothiocyante (FITC) as described previously. ${ }^{20}$ Briefly, different serotypes of $K$. pneumoniae were individually incubated overnight at $37^{\circ} \mathrm{C}$. The concentration was approximated using photospectrometry. The bacteria were washed with PBS and labeled with $0.1 \mathrm{mg} / \mathrm{ml}$ FITC (Sigma-Aldrich, St Louis, MO, USA) in

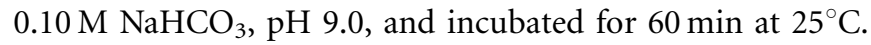
Unbound fluorochrome was washed away with PBS in three cycles of centrifugation $(13000 \mathrm{rpm}, 10 \mathrm{~min})$. The FITClabeled bacteria were resuspended in PBS to a concentration of $2 \times 10^{8}$ cells $/ \mathrm{ml}$, divided into equal volumes, and stored at $-70^{\circ} \mathrm{C}$ before use.

The phagocytosis assay was performed using modified flow cytometry with mouse serum and neutrophils. ${ }^{20} \mathrm{~A}$ mixture of labeled bacteria, the neutrophil suspension, the pooled mouse serum and PBS ( $\mathrm{pH}$ 7.4) was divided and incubated for 5 and $15 \mathrm{~min}$, respectively, in a shaking water bath at $37^{\circ} \mathrm{C}$. The supernatant was removed after centrifugation, the cell pellet was resuspended in ice-cold PBS solution and ethidium bromide solution was added before measurement to suppress the extracellular fluorescence. The ingested percentage of bacteria ( $n=6 /$ group/time point) was assessed using a FACScan (Becton Dickinson Immunocytometry Systems, San Jose, CA, USA) emitting an argon laser beam at $488 \mathrm{~nm}$ for detection of FITC fluorescence. The mean percentage of neutrophils that carried FITC-stained bacteria after 15 min of incubation in six successive trials was used as the phagocytosis rate.

\section{Preparation of Bacteria for Intraperitoneal Injection}

The bacterial concentration was determined by measuring the optical density at $600 \mathrm{~nm}$. The bacteria were then diluted to the desired concentrations in a $0.1-\mathrm{ml}$ inoculum, which was administered to the mice intraperitoneally (i.p.). An aliquot of the K. pneumoniae suspension used for inoculation was also serially diluted and placed onto Mueller-Hinton agar plates for determination of the actual colony-forming unit (cfu) of the injected bacteria.

\section{Determination of $\mathbf{L D}_{\mathbf{5 0}}$}

A 10 -fold serial dilution of $K$. pneumoniae cfu was prepared and the BALB/c mice were injected i.p. with $0.1 \mathrm{ml}$ of each concentration. Six mice were used for each bacterial concentration. Mice were observed daily for 14 days. The survival of the inoculated mice was recorded, and the 50\% lethal dose $\left(\mathrm{LD}_{50}\right)$ was calculated using SigmaPlot version 7.0 from SPSS (Chicago, IL, USA).

\section{Bacterial Burden in the Liver after i.p. Injection of K1, $K 2, K 62$ and $\Delta K 1$}

The mice were sacrificed with $\mathrm{CO}_{2}$ inhalation at specific time intervals ( $n=3 /$ group/time point) to measure the bacterial burdens in the livers. The livers were homogenized with $5 \mathrm{ml}$ of sterile saline and then serially diluted with sterile saline 
and plated onto Muller-Hinton agar. After incubation for $18 \mathrm{~h}$ at $35^{\circ} \mathrm{C}$, viable bacteria counts were calculated.

\section{Liver Pathology}

$\mathrm{BALB} / \mathrm{c}$ mice were injected i.p. with the K. pneumoniae serotypes $\mathrm{K} 1, \mathrm{~K} 2$ and $\mathrm{K} 62$ as well as the $\Delta \mathrm{K} 1$ mutant at $<10^{1}$ cfu for all tested strains and $\sim 2.9 \times 10^{5} \mathrm{cfu}$ for K62 and $\Delta \mathrm{K} 1$. The mice ( $n=5 /$ group/time point) were then sacrificed at $3 \mathrm{~h}$ and 1, 2 and 3 days after i.p. injection, and the livers were removed aseptically. Tissues were fixed in $10 \%(\mathrm{v} / \mathrm{v})$ formaldehyde and embedded in paraffin. The histological sections were examined after hematoxylin and eosin (H\&E) staining, and the bacteria were visualized with Giemsa staining and Gram staining. A semi-quantitative analysis was performed using a modified necrosis score (no lesion $=0$; infiltration of neutrophils $=1$; focal necrosis $=2$; submassive necrosis $=3$; massive necrosis + thrombotic lesions $=4$ ), as previously described. $^{21}$

\section{Kinetics of Inflammatory Cytokine and CXC Chemokine Production in the Liver and Serum}

Cytokine concentrations in the liver tissue and serum were measured ( $n=5 /$ group/time point) with a mouse cytokine 10-plex antibody bead kit (R\&D Systems, Minneapolis, MN, USA). Tumor necrosis factor (TNF) $-\alpha$, interleukin (IL)- $1 \beta$, IL- 6 and IL-10 levels were determined by ELISA according to the manufacturer's instructions. Pure K. pneumoniae (O1; K2) lipopolysaccahride (LPS, Sigma-Aldrich, 20, 200, $1000 \mu \mathrm{g} / \mathrm{ml}$ ) was used as a control. The minimal detectable protein concentration was $10 \mathrm{pg} / \mathrm{ml}$.

Macrophage inflammatory protein (MIP)-2 and keratinocyte-derived chemokine (KC) expression were detected using the mouse CXCL2/MIP-2 and CXCL1/KC Quantikine ELISA Kit (R\&D Systems). All samples were tested in triplicate.

\section{Statistical Analysis}

All data are expressed as mean values \pm s.d. The KaplanMeier method was used to evaluate the survival rate. Statistical analyses of data were performed using Mann-Whitney $U$-test for not normally distributed data. $P<0.05$ was considered as statistically significant.

\section{RESULTS}

\section{Phagocytosis Assay and Determination of Survival Differences in Mice following i.p. Injection of K. pneumoniae Serotypes K1, K2, K62 and $\Delta K 1$}

The phagocytosis assay ( $n=6 /$ group/time point) showed that strains of serotypes $\mathrm{K} 1\left(\mathrm{magA}^{+}, r m p A^{+}\right.$, aerobactin $\left.{ }^{+}\right)$and $\mathrm{K} 2\left(\mathrm{magA}^{-}, r m p A^{+}\right.$, aerobactin $\left.{ }^{+}\right)$were significantly more resistant to mouse neutrophil phagocytosis at $15 \mathrm{~min}$ (Figure 1) than those of serotype $\mathrm{K} 62\left(\mathrm{magA}^{-}, \operatorname{rmp} A^{-}\right.$, aerobactin $\left.{ }^{-}\right)$and the $\triangle \mathrm{K} 1$ mutant $\left(\mathrm{magA}^{+}, \operatorname{rmp} A^{+}\right.$, aerobactin $\left.{ }^{+}\right)(P<0.05)$. The encapsulated K62 strain was also slightly more resistant to neutrophil phagocytosis than the acapsulated $\Delta \mathrm{K} 1$ mutant but

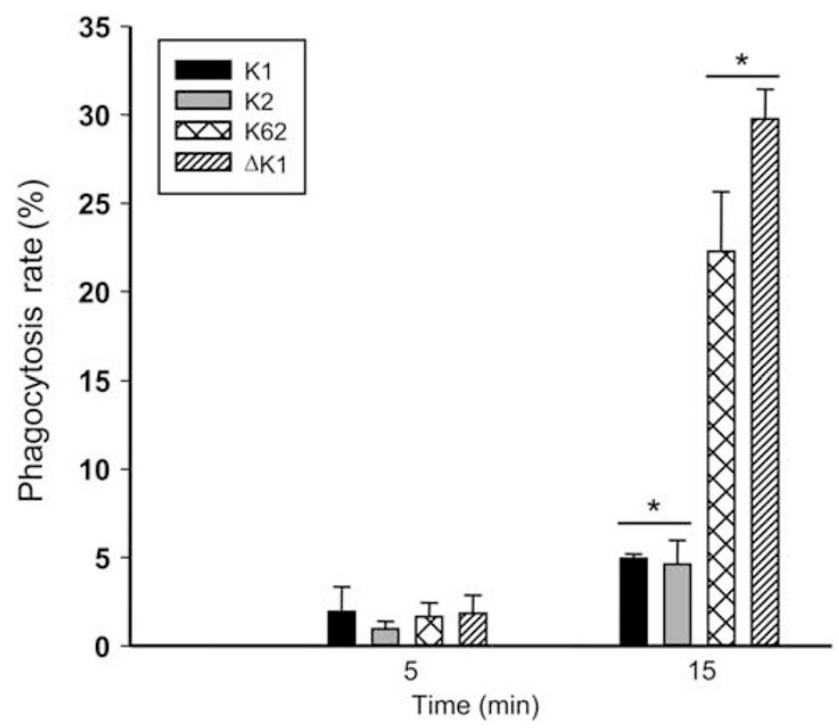

Figure $1 \mathrm{~A}$ comparison of mouse neutrophil phagocytosis assays among K. pneumoniae serotypes $\mathrm{K} 1\left(\mathrm{mag}^{+}, \mathrm{rmpA}^{+}\right.$, aerobactin $\left.{ }^{+}\right), \mathrm{K} 2\left(m a g A^{-}\right.$, $r m p A^{+}$, aerobactin $\left.{ }^{+}\right), \mathrm{K} 62\left(m a g A^{-}, r m p A^{-}\right.$, aerobactin $\left.{ }^{-}\right)$and $\Delta \mathrm{K} 1\left(m a g A^{+}\right.$, $r m p A^{+}$, aerobactin ${ }^{+}$). $\mathrm{K} 1$ and $\mathrm{K} 2$ strains were significantly more resistant to mouse neutrophil phagocytosis than $\mathrm{K} 62$ and $\Delta \mathrm{K} 1$ strains ( $n=6 /$ group/ time point). Values are means \pm s.d. ${ }^{*} P<0.05$ compared with $K 1 / K 2$ group and $\mathrm{K} 62 / \Delta \mathrm{K} 1$ group, Mann-Whitney $U$-test.

without statistical significance. Intraperitoneal injection was performed with seven different doses of each isolate, with each dose increasing by 10 -fold (from $10^{1}$ to $10^{6} \mathrm{cfu}$ ). The $\mathrm{LD}_{50}$ for the $\mathrm{K} 1$ and $\mathrm{K} 2$ strains was $<10^{1} \mathrm{cfu}$. All mice ( $n=6$ per group) died within 5 days of inoculation. For the K62 and $\Delta \mathrm{K} 1$ strains, all $\mathrm{LD}_{50}$ values were $>1 \times 10^{6} \mathrm{cfu}$, and all mice survived 14 days after inoculation. Intraperitoneal injection in each group of mice revealed that $\mathrm{K} 1\left(\mathrm{magA}^{+}, \mathrm{rmpA}^{+}\right.$, aerobactin $\left.^{+}\right)$and $\mathrm{K} 2$ $\left(m a g A^{-}, r m p A^{+}\right.$, aerobactin $\left.^{+}\right)$were significantly $(P<0.001)$ more virulent than the $\Delta \mathrm{K} 1$ mutant $\left(m a g A^{+}, r m p A^{+}\right.$, aerobactin $\left.^{+}\right)$and $\mathrm{K} 62\left(m a g A^{-}, r m p A^{-}\right.$, aerobactin $\left.{ }^{-}\right)$isolates (Figure 2).

\section{Determination of Viable Bacterial Counts in the Liver}

In total, four sets of mice ( $n=3 /$ group/time point) were challenged with $<10^{1}$ cfu of $\mathrm{K} 1\left(\mathrm{magA}^{+}, \operatorname{rmp} A^{+}\right.$, aerobactin $\left.^{+}\right), \mathrm{K} 2\left(m a g A^{-}, r m p A^{+}\right.$, aerobactin $\left.{ }^{+}\right), \mathrm{K} 62\left(m a g A^{-}\right.$, $r m p A^{-}$, aerobactin $\left.{ }^{-}\right)$and the $\Delta \mathrm{K} 1$ mutant $\left(m a g A^{+}, r m p A^{+}\right.$, aerobactin $\left.^{+}\right)$. Furthermore, two additional sets of mice ( $n=3$ /group/time point) were challenged with $\sim 2.9 \times 10^{5}$ cfu of K62 and $\Delta K 1$. No bacteria were counted in the mice challenged with $<10^{1}$ cfu of K62 and $\Delta \mathrm{K} 1$. The viable bacteria counts immediately after injection and after sacrifice at $3 \mathrm{~h}$ were much higher in the high-dose $\left(\sim 2.9 \times 10^{5} \mathrm{cfu}\right) \mathrm{K} 62$ and $\Delta \mathrm{K} 1$ inoculant groups than in the low-dose $\left(<10^{1} \mathrm{cfu}\right)$ $\mathrm{K} 1 / \mathrm{K} 2$ groups. The viable $K$. pneumoniae counts declined rapidly between $3 \mathrm{~h}$ and 3 days after inoculation in the K62 and $\Delta \mathrm{K} 1$ groups, while the number of viable K. pneumoniae in the livers of the $\mathrm{K} 1$ and $\mathrm{K} 2$ groups increased in a 


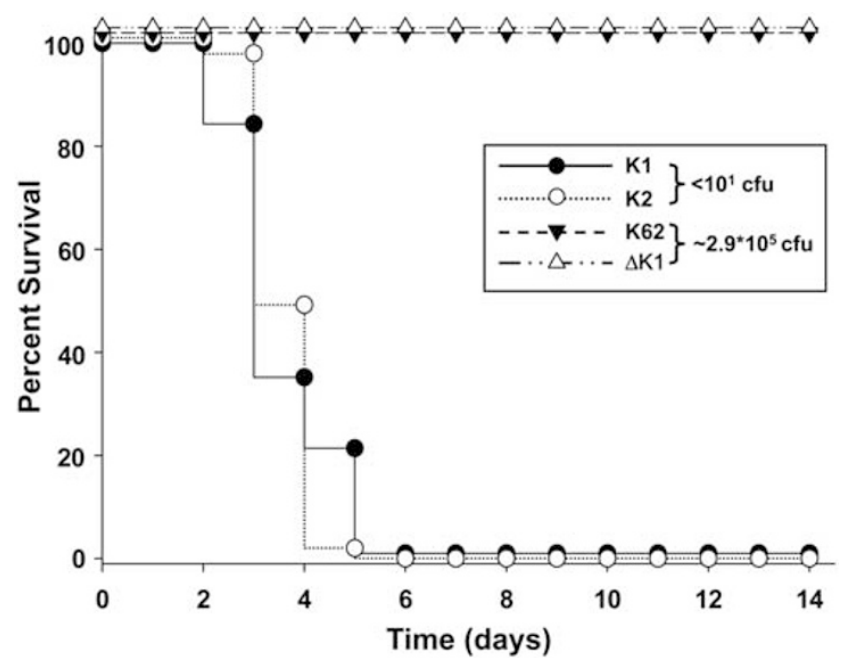

Figure 2 Survival differences of mice after i.p. injection of inoculants with different strains of K. pneumoniae ( $n=6 /$ group). All K1- $\left(m a g A^{+}, r m p A^{+}\right.$, aerobactin $\left.^{+}\right)$and $\mathrm{K} 2-\left(m a g A^{-}, r m p A^{+}\right.$, aerobactin $\left.{ }^{+}\right)$infected mice (i.p. dose $<10^{1} \mathrm{cfu}$ ) died within 5 days, and all K62- $\left(m a g A^{-}, r m p A^{-}\right.$, aerobactin $\left.{ }^{-}\right)$and $\Delta \mathrm{K} 1$ mutant- $\left(\mathrm{magA}^{+}, \mathrm{rmpA}^{+}\right.$, aerobactin $\left.{ }^{+}\right)$infected mice (i.p. dose $\left.\sim 2.9 \times 10^{5} \mathrm{cfu}\right)$ survived 14 days after inoculation $(P<0.001$ for $\mathrm{K} 1$ vs $\Delta \mathrm{K} 1$, and $\mathrm{K} 2$ vs $\mathrm{K} 62, \chi^{2}$ test).

time-dependent manner (Figure 3). No viable K. pneumoniae were found on immediate sacrifice after low-dose $\left(<10^{1} \mathrm{cfu}\right)$ i.p. injection in the $\mathrm{K} 1 / \mathrm{K} 2$ groups. Although relatively low $K$. pneumoniae counts were detected $3 \mathrm{~h}$ after inoculation with $\mathrm{K} 1$ and $\mathrm{K} 2$, the number of viable counts increased rapidly thereafter compared with inoculation with $\mathrm{K} 62$ and the acapsular $\Delta \mathrm{K} 1$ mutant $(P<0.001$ when compared with $\mathrm{K} 1 / \mathrm{K} 2$ group and the K62/ $\Delta \mathrm{K} 1$ group) Comparison of the encapsulated $\mathrm{K} 62\left(m a g A^{-}, r m p A^{-}\right.$, aerobactin $\left.{ }^{-}\right)$and acapsulated $\Delta \mathrm{K} 1$ mutant $\left(m a g A^{+}, r m p A^{+}\right.$, aerobactin $\left.{ }^{+}\right)$with the same high-dose $\left(\sim 2.9 \times 10^{5} \mathrm{cfu}\right)$ inoculation at all time points revealed that the increasing viable cell counts in the avirulent encapsulated K62 strain were also significantly higher than those of the acapsular $\Delta \mathrm{K} 1$ mutant $(P<0.05)$.

\section{Histopathology Findings}

Low- and high-dose mice from the bacterial burden experiments were used to assess the dose-associated liver injury ( $n=5 /$ group/time point). The variation in the scores calculated for different strains with different doses of inoculum is presented in Table 1. Histological sections of liver tissues showed no evidence of inflammation after inoculation with low-dose $\left(<10^{1} \mathrm{cfu}\right) \mathrm{K} 62$ and $\Delta \mathrm{K} 1$ strains. However, the livers of mice inoculated with the low-dose $\left(<10^{1} \mathrm{cfu}\right) \mathrm{K} 1$ strain showed acute inflammatory cell infiltration in the perivascular regions and sinusoids and a few small, discrete areas of microabscesses with neutrophilic infiltration as early as $3 \mathrm{~h}$ after injection (Figure $4 \mathrm{a}$ ), and multiple foci of necrosis were observed at day 1 (Figure $4 \mathrm{c}$ ). The inflammatory process after inoculation with the $\mathrm{K} 2$ strain $\left(<10^{1} \mathrm{cfu}\right)$ was as severe

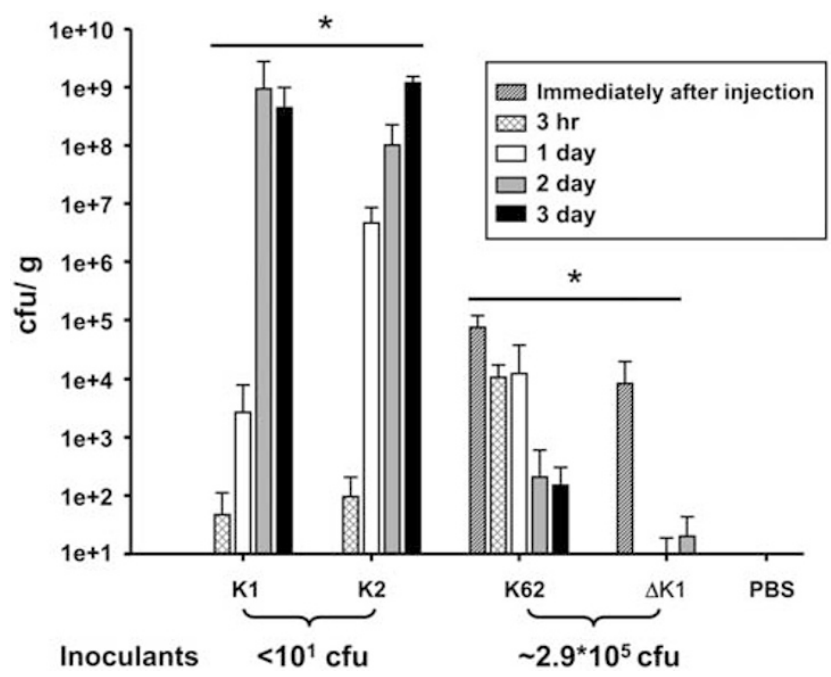

Figure 3 Bacterial count in mouse livers after low-dose inoculation $\left(<10^{1}\right.$ $\mathrm{cfu})$ with $K$. pneumoniae serotypes $\mathrm{K} 1\left(\mathrm{magA}^{+}, \mathrm{rmpA} A^{+}\right.$, aerobactin $\left.{ }^{+}\right)$and $\mathrm{K} 2\left(\mathrm{magA}^{-}, \mathrm{rmpA} A^{+}\right.$, aerobactin $\left.^{+}\right)$and high-dose $\left(\sim 2.9 \times 10^{5} \mathrm{cfu}\right)$ inoculation with $\mathrm{K} 62\left(\mathrm{magA}^{-}, r m p A^{-}\right.$, aerobactin $\left.{ }^{-}\right)$and the $\Delta \mathrm{K} 1$ mutant $\left(\mathrm{magA}^{+}, r \mathrm{mpA} A^{+}\right.$, aerobactin $\left.{ }^{+}\right)$. Increasing bacterial counts were found in the livers of mice ( $n=3 /$ group/time point) sacrificed immediately and up to 3 days after $\mathrm{K} 1$ and $\mathrm{K} 2$ inoculation. Viable bacterial counts were undetectable following low-dose inoculation ( $<10^{1} \mathrm{cfu}$ ) with $\mathrm{K} 62$ and $\Delta \mathrm{K} 1$ mutant. Viable bacterial counts increased immediately after i.p. injection of high-dose $\left(\sim 2.9 \times 10^{5} \mathrm{cfu}\right) \mathrm{K} 62$ and $\Delta \mathrm{K} 1$ mutant but then declined rapidly. Viable $\Delta \mathrm{K} 1$ mutant cells were almost undetectable $3 \mathrm{~h}$ post-injection. $\left({ }^{*} P<0.001\right.$ compared with $\mathrm{K} 1 / \mathrm{K} 2$ group and $\mathrm{K} 62 / \Delta \mathrm{K} 1$ group at all time points, Mann-Whitney U-test).

as for the $\mathrm{K} 1$ strain (Figure $4 \mathrm{~b}$ ). In addition to multifocal microabscesses in the liver, thrombi in sinusoids (Figure 4d) were also observed at day 1 , and multiple foci of coagulative necrosis were randomly distributed throughout the liver. Giemsa staining of serotype K1 liver sections revealed a large amount of bacteria distributed in the sinusoids (Figure 4e); these bacteria proved to be Gram-negative bacilli (Figure 4f). The histopathogical sections at day 3 are shown in Figure 5. The liver parenchyma was infiltrated by large numbers of neutrophils with moderate to severe hepatocyte degeneration and massive necrosis recognized after low-dose $\left(<10^{1} \mathrm{cfu}\right)$ inoculation of serotype K1 and K2 strains. After high-dose $\left(\sim 2.9 \times 10^{5} \mathrm{cfu}\right)$ inoculation with $\mathrm{K} 62$ and $\Delta \mathrm{K} 1$ strains, only a few inflammatory cells without obvious necrosis were observed in the liver at day 3 .

\section{Cytokine Expression in the Liver and Serum after Inoculation with Serotypes K1/K2, K62 and $\Delta K 1$}

Cytokines in the liver and serum were determined in all experimental groups $(n=5 /$ group/time point $)$ at $3 \mathrm{~h}$ and at days 1, 2 and 3 after inoculation. Low-dose $\left(<10^{1} \mathrm{cfu}\right)$ inoculation with serotypes $\mathrm{K} 1$ and $\mathrm{K} 2$ resulted in the production of TNF- $\alpha$, IL- $1 \beta$ and IL- 6 at $3 \mathrm{~h}$. These cytokine levels rapidly increased at days 1,2 and 3 (Figure $6 \mathrm{a}-\mathrm{c}$ and e-g) but were not detected after inoculation with K62 


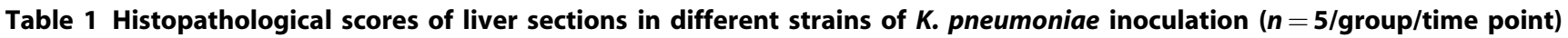

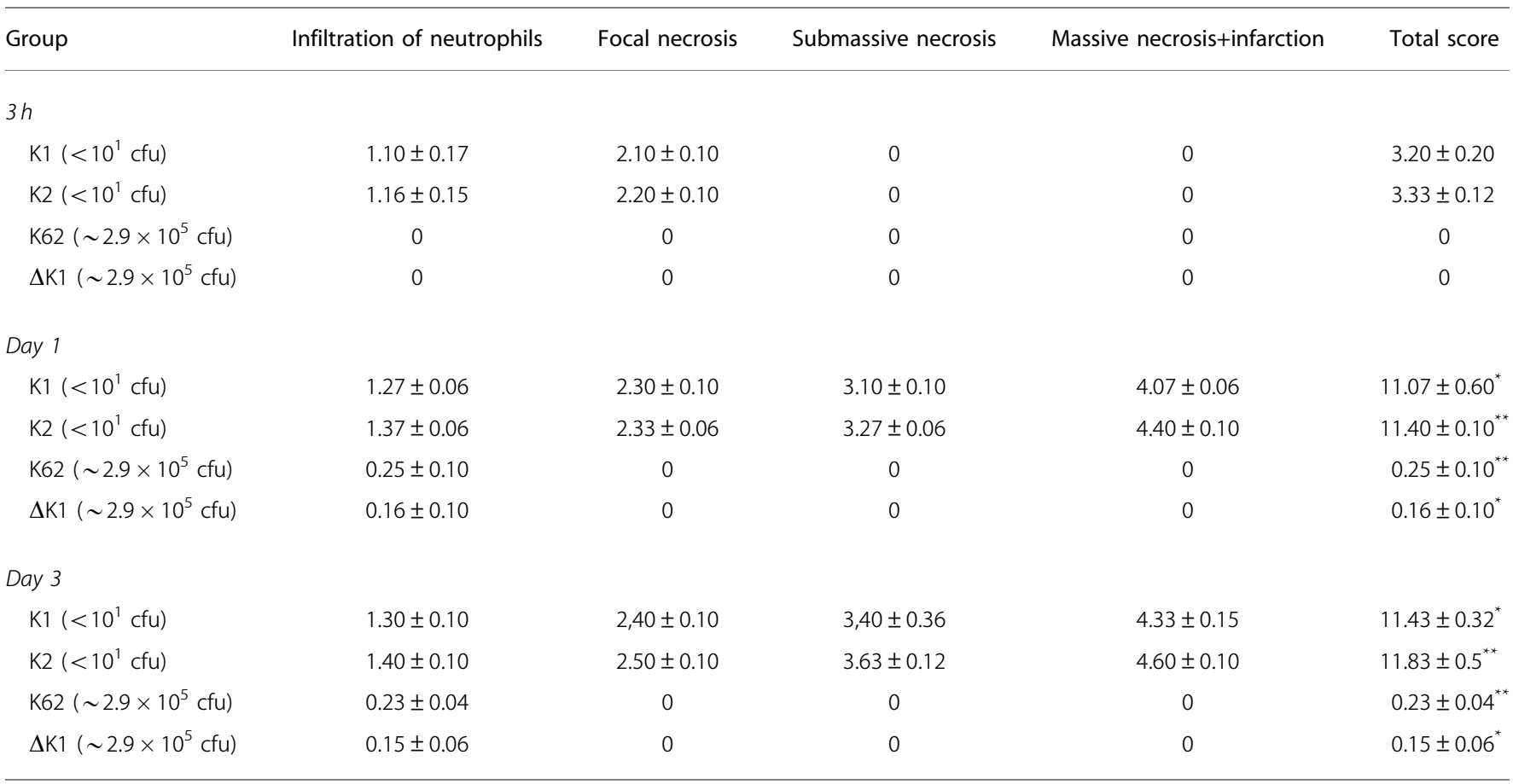

Data are mean \pm s.d. Scoring differences between the groups were compared using one-way ANOVA.

${ }^{*} \mathrm{P}<0.0001$ compared with $\mathrm{K} 1$ and $\Delta \mathrm{K} 1 ;{ }^{* *} \mathrm{P}<0.0001$ compared with $\mathrm{K} 2$ and $\mathrm{K} 62$.

and the $\Delta \mathrm{K} 1$ mutant. Although high-dose inoculation $\left(\sim 2.9 \times 10^{5} \mathrm{cfu}\right)$ with K62 initially resulted in higher TNF- $\alpha$, IL-1 $\beta$ and IL6 production in both liver and serum samples than low-dose K1 and K2 inoculation, the levels of these cytokines dramatically decreased at day 1 and reached a very low level $(<10 \mathrm{pg} / \mathrm{ml})$ at days 2 and 3 (Figure $6 \mathrm{a}-\mathrm{c}$ and $\mathrm{e}-\mathrm{g})$. TNF- $\alpha$, IL-1 $\beta$ and IL6 expression after high-dose inoculation with the $\Delta \mathrm{K} 1$ mutant was almost undetectable 1 day after inoculation (Figure 6a-c and e-g). After inoculation with serotypes K1 and K2, IL-10 expression was not detected in liver or serum samples at $3 \mathrm{~h}$ or 1 day (Figure $6 \mathrm{~g}$ and $\mathrm{h}$ ) but was detected at day 2, and expression had further increased at day 3. After inoculation with $200 \mu \mathrm{g}$ pure K2 LPS in controls, high-level expression of IL-10 was observed in the serum at $3 \mathrm{~h}$, but levels decreased rapidly from day 1 to day 3. IL-10 expression after inoculation with K62 and the $\Delta \mathrm{K} 1$ mutant was similar to the pure K2 LPS profile, as it was relatively lower in the liver than in serum samples. The IL-10 expression in the liver and serum samples of both of these groups tended to decline from $3 \mathrm{~h}$ to day 3 (Figure $6 \mathrm{~d}$ and $\mathrm{h}$ ). A comparison of the cytokine profiles of the highdose (K62 and $\Delta \mathrm{K} 1$ group) and low-dose (K1 and K2 group) injection groups revealed that TNF- $\alpha$, IL-1 $\beta$, IL6 and IL-10 production was significantly lower at 3 days after K62 and $\Delta$ K1 mutant inoculation $(P<0.001)$, even at high doses, indicating the rapid clearance of $\mathrm{K} 62$ and $\Delta \mathrm{K} 1$ mutant bacteria and the non-clearance and replication of serotype $\mathrm{K} 1 / \mathrm{K} 2$ bacteria.

\section{Determination of Neutrophil Influx into the Liver by Detection of MIP-2 and KC Production in the Liver and Serum}

MIP-2 and KC expression were not detected in serum or liver samples after low-dose inoculation $\left(<10^{1} \mathrm{cfu}\right)$ with $\mathrm{K} 62$ and $\Delta \mathrm{K} 1$ but were elevated between $3 \mathrm{~h}$ and 3 days after inoculation with low doses $\left(<10^{1} \mathrm{cfu}\right)$ of serotype K1/K2 (Figure 7). MIP-2 was detected within $3 \mathrm{~h}$ after high-dose $\left(\sim 2.9 \times 10^{5} \mathrm{cfu}\right)$ inoculation with $\mathrm{K} 62$ and the $\Delta \mathrm{K} 1$ mutant and inoculation with $200 \mu \mathrm{g}$ pure K2 LPS, but rapidly declined in these groups from day 1 to day 3 (Figure $7 \mathrm{a}$ and b). KC expression showed a relatively slow decline after highdose inoculation with $\mathrm{K} 62$ and the $\Delta \mathrm{K} 1$ mutant (Figure $7 \mathrm{c}$ and $d$ ).

\section{DISCUSSION}

$K$. pneumoniae have been documented as the major pathogenic cause of pyogenic liver abscess (PLA) in Taiwan since the 1980s. ${ }^{1,10,22,23}$ Recent studies from North and Southeast Asia have emphasized serotypes $\mathrm{K} 1$ and $\mathrm{K} 2$ as major causes of PLA. $^{8,10}$ Our initial experiments comparing the survival differences among groups of mice inoculated with serotypes $\mathrm{K} 1\left(m a g A^{+}, r m p A^{+}\right.$, aerobactin $\left.{ }^{+}\right), \mathrm{K} 2\left(m a g A^{-}, r m p A^{+}\right.$, aerobactin $\left.^{+}\right), \quad \mathrm{K} 62\left(m a g A^{-}, \quad r m p A^{-}\right.$, aerobactin $\left.{ }^{-}\right)$and the $\Delta \mathrm{K} 1$ mutant $\left(m a g A^{+}, r m p A^{+}\right.$, aerobactin $\left.{ }^{+}\right)$demonstrated that the $\Delta \mathrm{K} 1$ mutant had a substantially attenuated disease-causing ability similar to that of K62. Although this study confirmed that the $r m p A$-negative strains are less 
phagocytosis resistant or less virulent, even when encapsulated, ${ }^{10,12}$ it is unlikely that a single factor (eg, rmpA or aerobactin) could be singly responsible for virulence in PLA
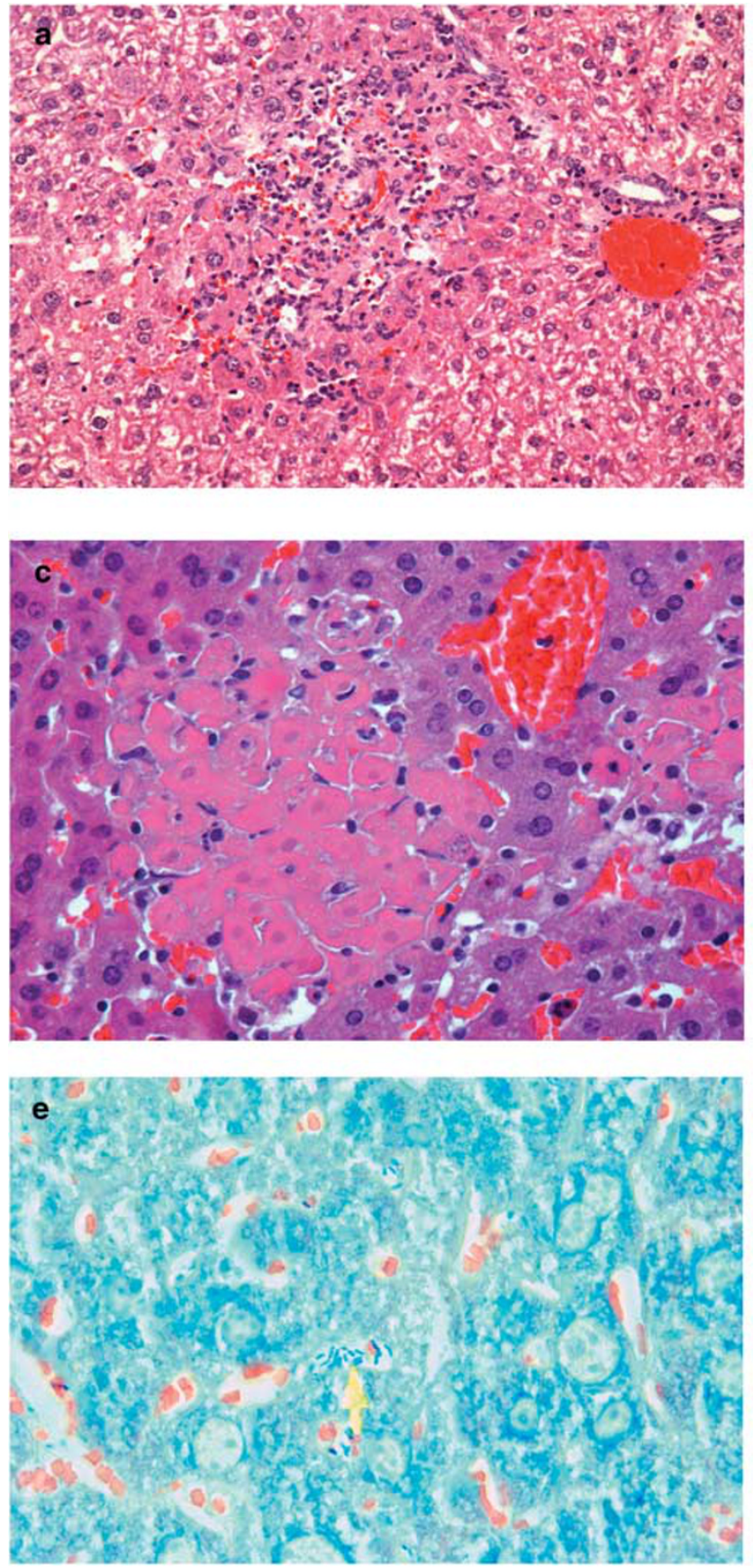

development because the $\Delta \mathrm{K} 1$ strain also carries the rmpA and aerobactin gene. Meanwhile, our phagocytosis assay study revealed that encapsulated K62 was also more resistant
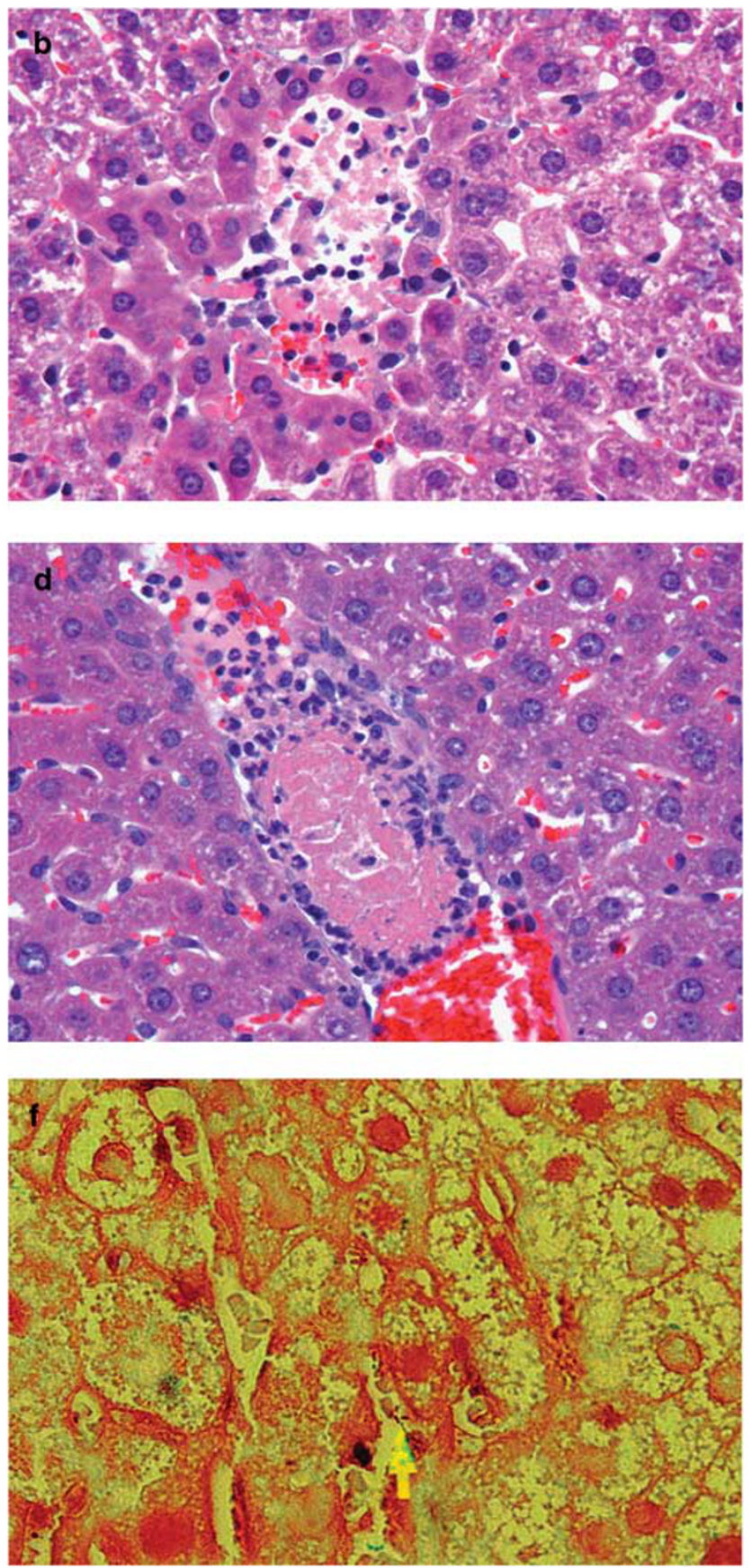

Figure 4 Liver histopathology after i.p. injection of different serotypes of $K$. pneumoniae ( $n=5 /$ group/time point). (a, b) Discrete areas of microabscesses with neutrophilic infiltrates at $3 \mathrm{~h}$ post low-dose $\left(<10^{1} \mathrm{cfu}\right) \mathrm{K} 1$ and $\mathrm{K} 2$ inoculation.(original magnification $\times 200$ and $\times 400$, respectively). (c) Hepatocyte necrosis was observed at day 1 (original magnification $\times 400$ ). (d) Thrombus in a distended sinusoid was observed at day 1 (original magnification $\times 400$ ). (e) Giemsa stain showed a large amount of bacilli in sinusoids (original magnification $\times 1000$ ). (f) Gram stain reveals many Gram-negative bacilli in sinusoids (original magnification $\times 1000$ ).

Figure 5 Liver histopathology after i.p. injection of different serotypes of $K$. pneumoniae ( $n=5 /$ group) at day 3. Areas of hepatocyte degeneration and/or necrosis with acute inflammatory cell infiltration were seen post low-dose $\left(<10^{1} \mathrm{cfu}\right)$ serotypes K1 and K2 injection. There were only mild inflammatory cell infiltration in the liver parenchyma in sections of mice after high-dose $\left(\sim 2.9 \times 10^{5} \mathrm{cfu}\right)$ inoculation of serotypes K62 and $\Delta \mathrm{K} 1$. $(H \& E$ stain, left column, original magnification $\times 100$; right column, original magnification, $\times 400)$. 

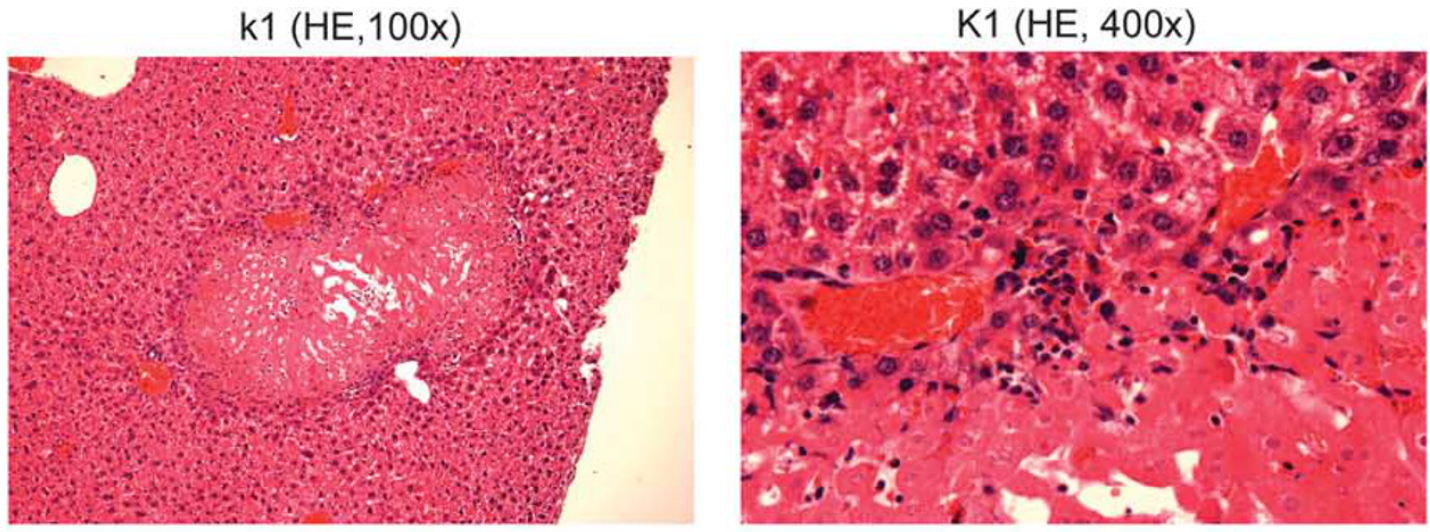

K2 (HE, 100x)

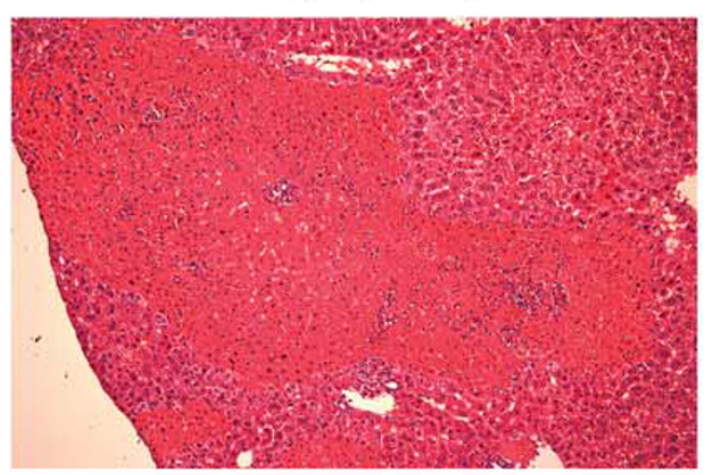

K2 (HE, 400x)

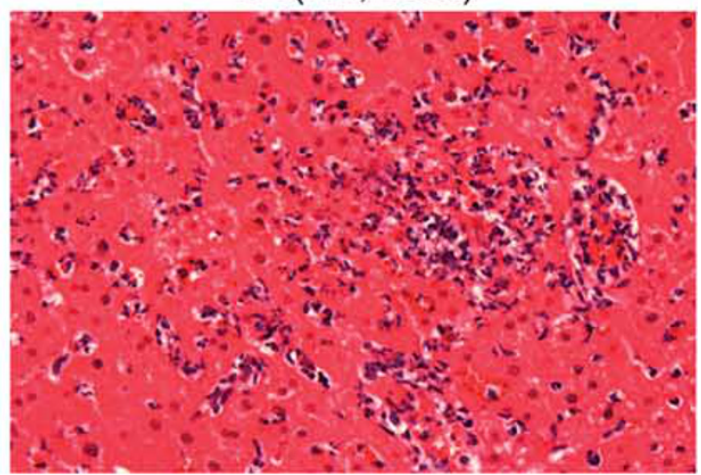

K62 (HE, 100x)
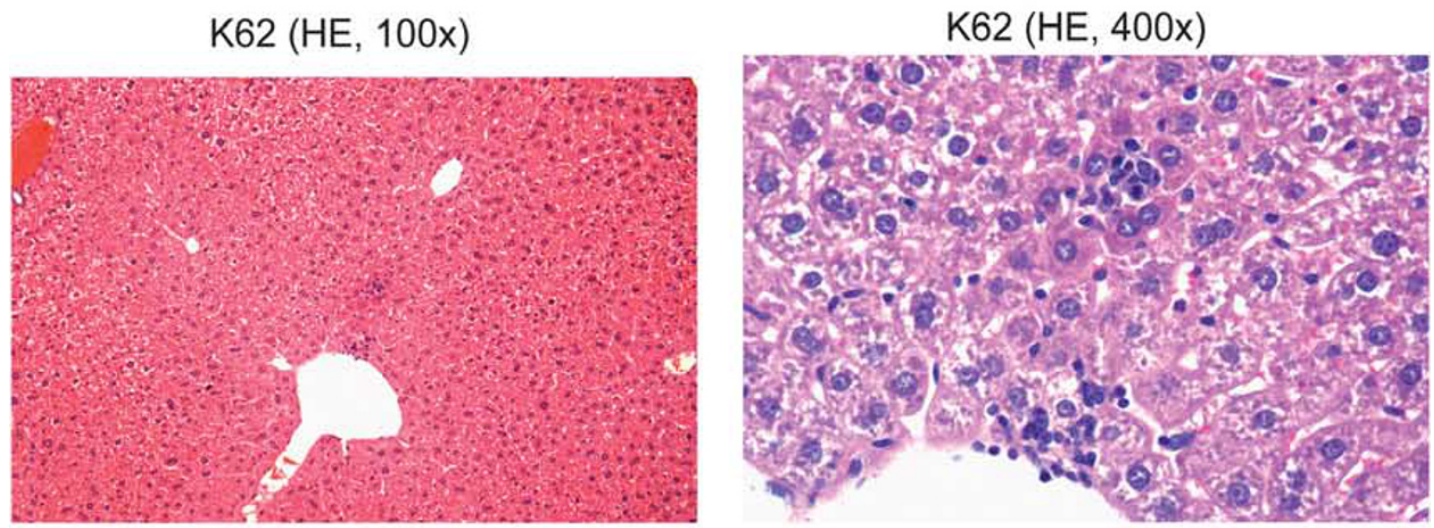

$\Delta \mathrm{K} 1(\mathrm{HE}, 100 \mathrm{x})$

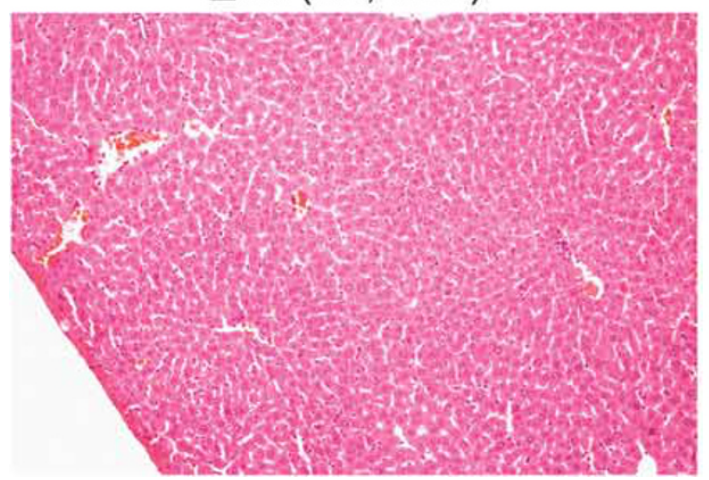

$\Delta \mathrm{K} 1(\mathrm{HE}, 400 \mathrm{x})$

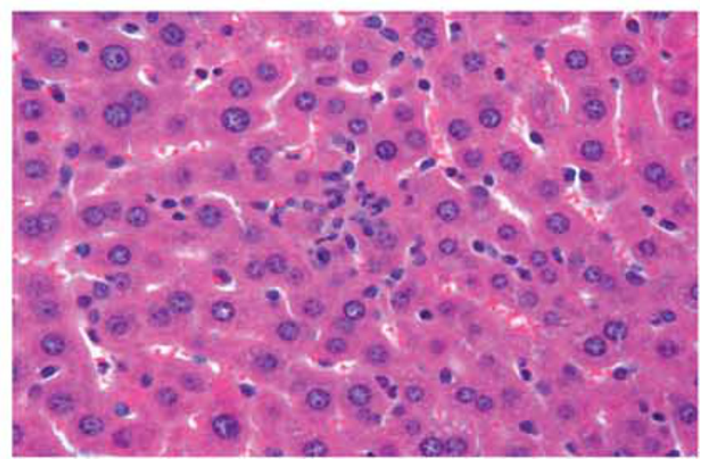


Liver
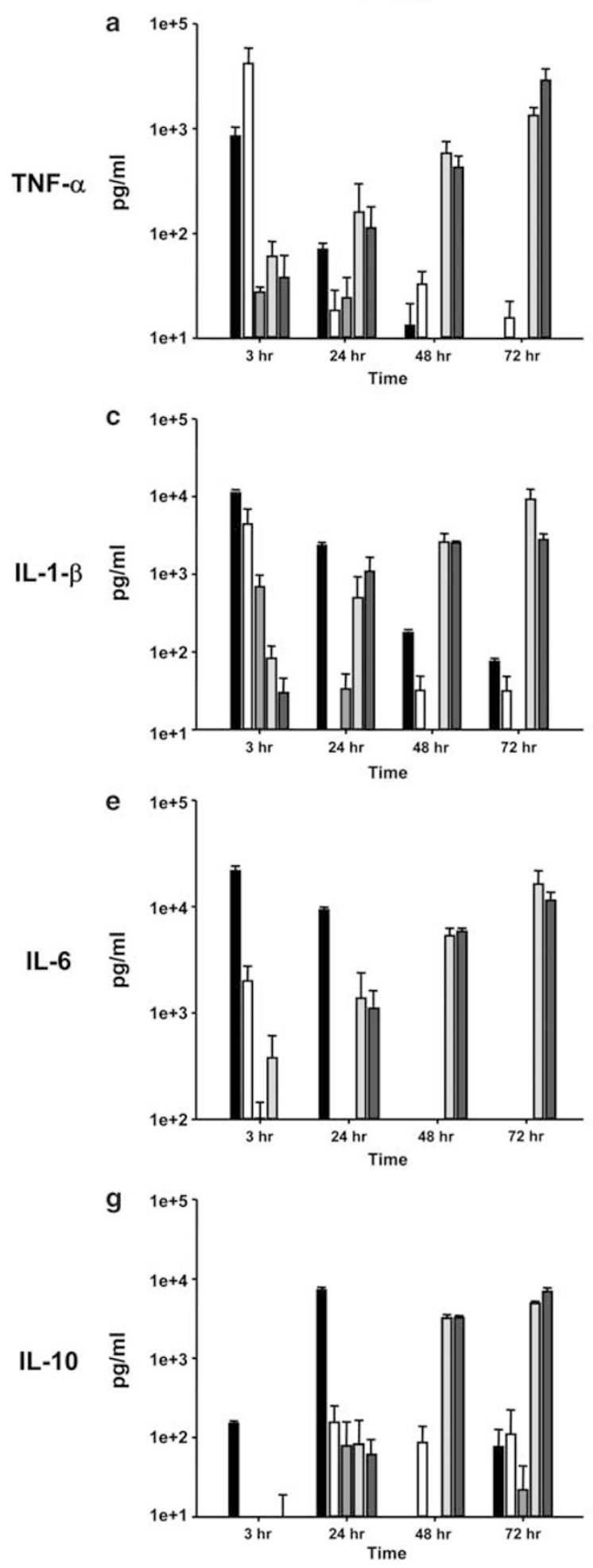

Serum
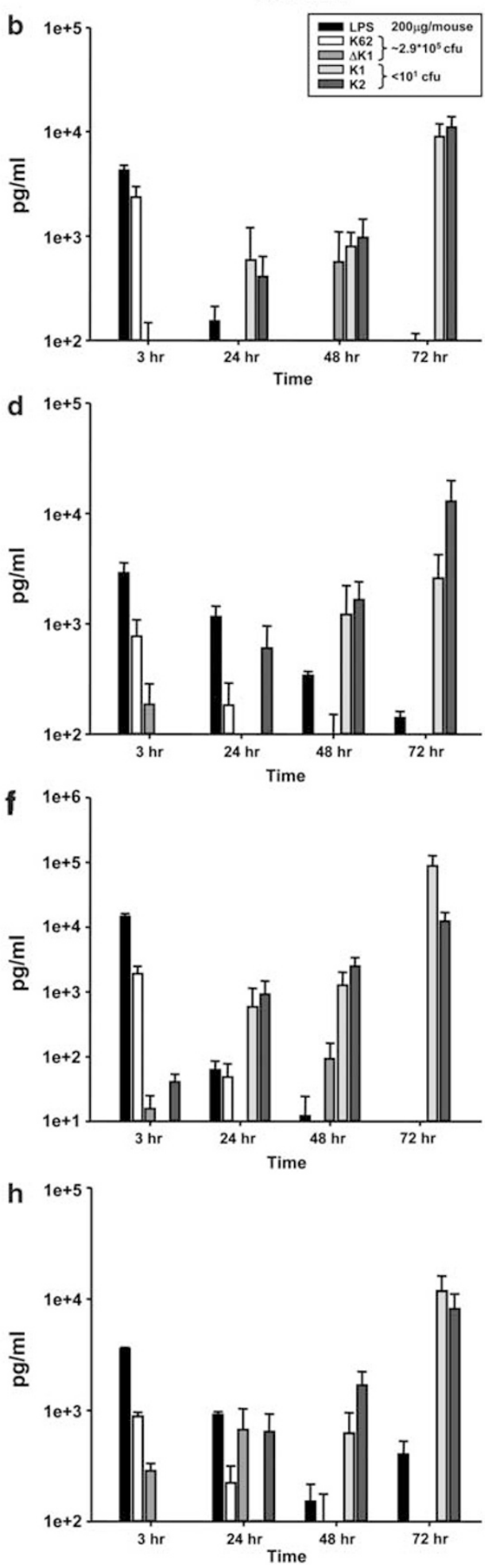

Figure 6 TNF- $\alpha$, IL-1 $\beta$, IL- 6 and IL-10 production in liver (a, $\mathbf{c}$, e and $\mathbf{g}$ ) and serum (b, d, $\mathbf{f}$ and $\mathbf{h})$. Elevated liver TNF- $\alpha$, IL-1 $\beta$, IL- 6 and IL-10 production occurred after low-dose inoculation ( $<10^{1} \mathrm{cfu}$ ) with K1 and K2 strains. TNF- $\alpha, \mathrm{IL}-1 \beta, \mathrm{IL}-6$ and IL-10 production were undetectable in mice inoculated with $\mathrm{K} 62$ and the $\Delta \mathrm{K} 1$ mutant at the same dose $\left(<10^{1} \mathrm{cfu}\right)$ used for K1 and K2. Decreased TNF- $\alpha, \mathrm{IL}-1 \beta$, IL- 6 and IL-10 production occurred after high-dose inoculation $\left(\sim 2.9 \times 10^{5} \mathrm{cfu}\right)$ with $\mathrm{K} 62, \Delta \mathrm{K} 1$ mutant and $200 \mu \mathrm{g}$ pure LPS. Liver homogenates and serum were prepared from Balb/c mice following i.p. inoculation at the indicated time points. Cytokine levels in the liver and serum were determined by ELISA. Values are means \pm s.d. $P<0.001$ compared with

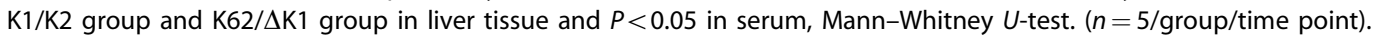


Liver
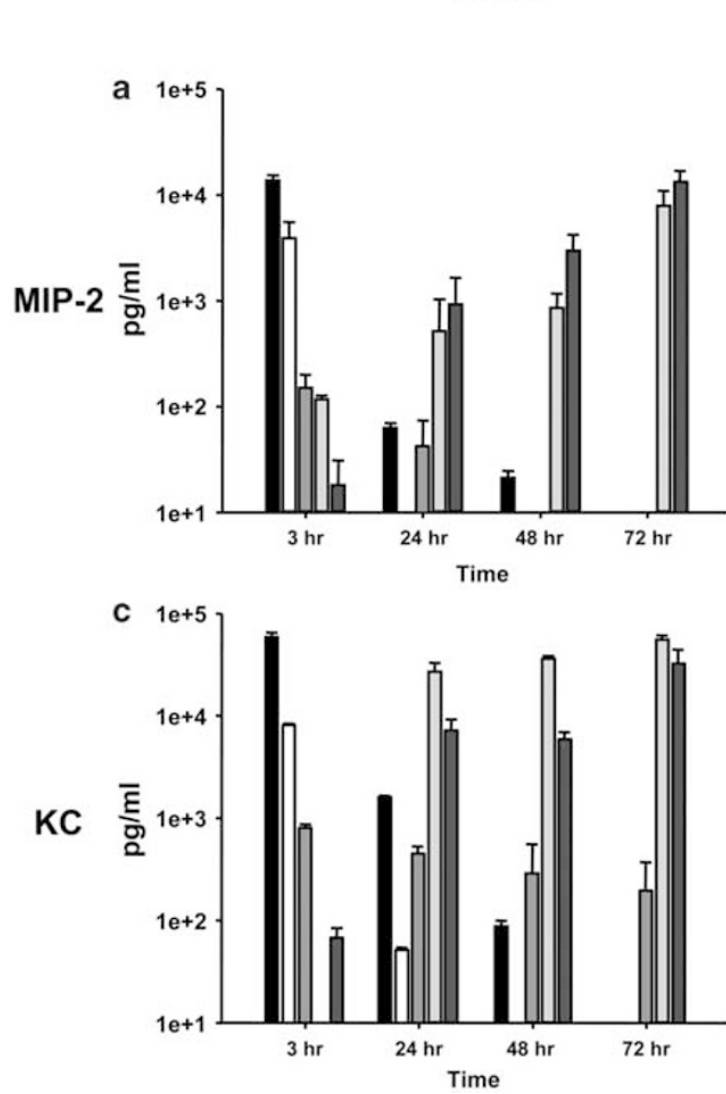

Serum
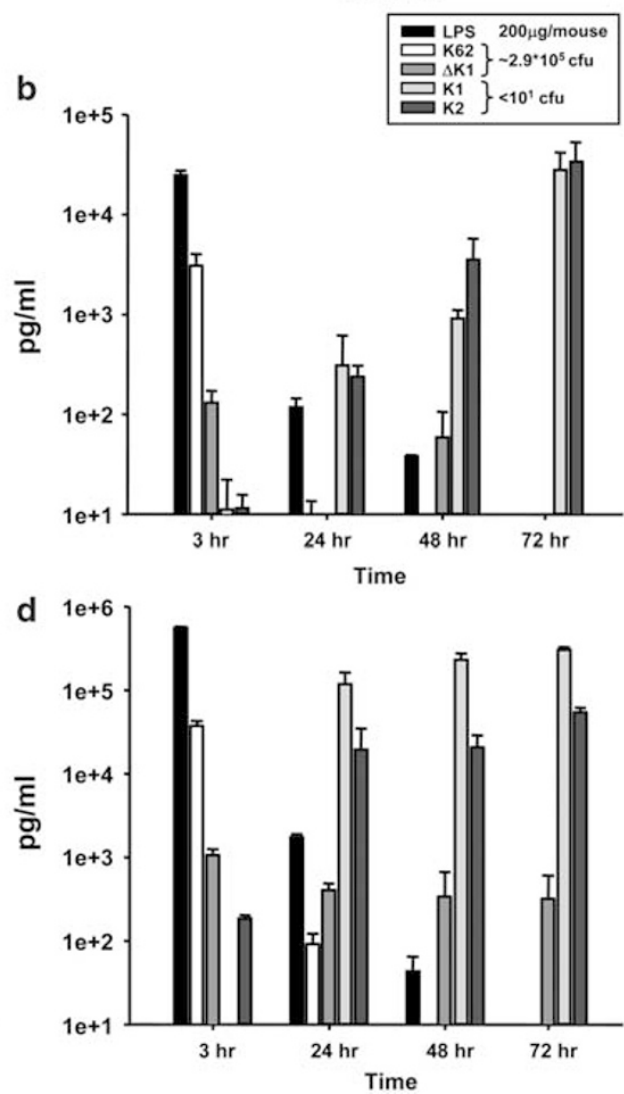

Figure 7 MIP-2 and KC detection in the livers (a, c) and serum (b, d) of mice on days 1,2 and 3 after inoculation with $\mathrm{K} 1$, K2, K62 and the $\Delta \mathrm{K} 1$ mutant ( $n=5$ /

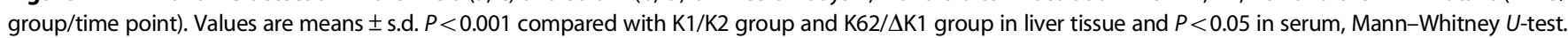

to neutrophil phagocytosis than the acapsulated $\Delta \mathrm{K} 1$ mutant. The increasing viable cell counts for avirulent, capsulated K62 were also significantly higher than those for the acapsular $\Delta \mathrm{K} 1$ mutant. Therefore, the role of the phagocyticresistant capsule in K. pneumoniae infections should not be underestimated. Recently, a 219-kb pLVPK plasmid from $K$. pneumoniae was reported to be associated with PLA development; however, not all $K$. pneumoniae PLA isolates $(66 \%, 23 / 35)$ were $t e r W^{+}-i u t A^{+}-r m p A^{+}$-sils ${ }^{+} .{ }^{24}$ Hence, the development of $K$. pneumoniae liver abscesses likely results from a combination of all virulence determinants, including the phagocytic-resistant capsule and hypermucoviscosity phenotype as well as the presence of $r m p A$, aerobactin and other virulence-associated genes.

In this study, the presence of LPS (O antigen) in $\Delta \mathrm{K} 1$ maintained a level of cytokine induction level similar to that observed after high-dose inoculation of K62. These findings indicate that the two surface polysaccharides, ie, the $\mathrm{O}$ and $\mathrm{K}$ antigens, conferred different functions. Our results showed that these surface antigens contribute to pathogenesis in different ways. In our phagocytic uptake assay, the capsule had a major role in phagocytic uptake, and the phagocytic resistance was shown to be serotype
$\mathrm{K}$ antigen specific. Mortality in the systemic infection model was not closely related to the dosage of $K$. pneumoniae for the serotypes used. Our mouse survival tests demonstrated that $\mathrm{K} 1$ and $\mathrm{K} 2$ strains isolated from liver abscesses were particularly virulent. For the serotype $\mathrm{K} 62$ and $\Delta \mathrm{K} 1$ strains, the $\mathrm{LD}_{50}$ values were all higher than $1 \times 10^{6} \mathrm{cfu}$, and all mice survived 14 days after inoculation. However, the $\mathrm{LD}_{50}$ for serotype $\mathrm{K} 1$ and $\mathrm{K} 2$ strains from liver abscess patients was $<10^{1} \mathrm{cfu}$. All mice inoculated with these strains died within 5 days. This finding is in agreement with previous studies showing that even in different species of mice, $\mathrm{K} 2$ strains may have high virulence, with an $\mathrm{LD}_{50}$ of $<5 \mathrm{cfu}^{25}$ In the present study, the increased mortality of mice inoculated with serotypes $\mathrm{K} 1 / \mathrm{K} 2$ was linked to the inability to clear bacteria, leading to peritonitis and bacterial overgrowth in multiple organs. This resulted in exposure to high levels of bacterial endotoxins, which finally caused multiple organ dysfunction syndrome and rapid death.

A surge in TNF- $\alpha$ was detected in liver tissue and serum $3 \mathrm{~h}$ after LPS administration, followed by a rapid decrease at day 1 post-injection. Although the TNF- $\alpha$ level was not detectable $3 \mathrm{~h}$ in serum after inoculation with serotypes K1 
and $\mathrm{K} 2$, a measurable level was reached at day 1 . Levels increased further at day 2 and peaked at day 3 in both liver tissue and serum. These findings could be due to the very small amount of bacteria (i.p. dose $<10^{1} \mathrm{cfu}$ ) in the inoculation. The mouse neutrophil phagocytosis model used in the present study and the human neutrophil phagocytosis model used in our previous study showed that serotypes K1 and $\mathrm{K} 2$ strains from liver abscesses had a high resistance to phagocytosis. ${ }^{20}$

Previous studies showed that the strains of $K$. pneumoniae expressing Man- $\alpha 2 / 3$-Man or Rha- $\alpha 2 / 3$-Rha sequences in their CPS structure could be recognized by macrophage mannose receptors and readily ingested by macrophages. ${ }^{26,27}$ Interestingly, serotypes $\mathrm{K} 1$ and $\mathrm{K} 2$ of $\mathrm{K}$. pneumoniae strains lack the Man- $\alpha 2 / 3$-Man or Rha- $\alpha 2 / 3$-Rha sequences in their CPS structure, are not recognized by the macrophage lectin, they would be able to escape from lectinophagocytosis and proliferate, and will then express other virulent factors. Our previous study also demonstrated that after $30 \mathrm{~min}$ of incubation with neutrophils, the cell wall structure of $\mathrm{K} 1$ in the phagocytosed cells still remain intact without any morphological alterations indicating resistant to lysis. In contrast, the phagocytosed cells of K6 revealed a rupture cell wall and complete lysis within $30 \mathrm{~min}$ of incubation with neutrophils. ${ }^{20}$ Our previous studies also showed that the K1 and $\mathrm{K} 2$ isolates from liver abscess were significantly more resistant to phagocytosis than those of non-K1/K2 isolates from liver abscess or non-liver abscess. ${ }^{20}$ Recent study demonstrated that $\mathrm{K} 1$ isolates from liver abscess contained a high level of fucose in their CPS structure, it might also be a contribution factor to phagocytic resistance. ${ }^{28}$

Because of phagocytosis resistance and intracellular killing after i.p. inoculation, the number of viable counts increased rapidly, resulting in high-level TNF- $\alpha$ production at days 1,2 and 3. In contrast, viable counts of the phagocytic-susceptible serotype K62 declined rapidly even with high-dose inoculation, leading to a rapid decrease in cytokine and chemokine expression. TNF- $\alpha$ levels were almost undetectable after highdose $\Delta \mathrm{K} 1$ mutant inoculation at all time points, indicating that acapsulated $\Delta \mathrm{K} 1$ was much more easily cleared by neutrophils than serotype K62.

This study found a significant correlation between cytokine production and histopathological changes in liver tissue. In addition to multifocal microabscesses in the livers of mice in the K1 and K2 groups, thrombi were also observed at day 1, and multiple foci of coagulative necrosis were randomly distributed throughout the liver, especially in the K2 group. These results are compatible with previous studies that the amount of endogenous TNF activity is related to the severity of hemorrhagic and thrombotic lesions in the visceral organs, especially focal coagulative necrosis in the liver and kidney. ${ }^{29,30}$ IL-6 confers anti-inflammatory effects and hepatoprotective ability by downregulating TNF after activating the signal transducer and activator of transcription-3 protein in hepatocytes. It also has promotes liver regeneration after liver injury. ${ }^{31}$ Like IL-6, IL-10 can also inhibit TNF- $\alpha$ and IL-1 $\beta$ production by macrophages and peripheral monocytes, at least in part by downregulating the transcription of TNF- $\alpha$ mRNA in response to LPS. ${ }^{32}$ The competing expression of pro- and anti-inflammatory cytokines may determine the severity of inflammation, tissue damage and mortality. ${ }^{33}$ Gogos et al ${ }^{34}$ demonstrated that a high IL-10 to TNF- $\alpha$ ratio was associated with death in patients with severe sepsis. These findings were also confirmed in the present study. Although relatively high levels of TNF- $\alpha$, IL- $1 \beta$ and IL- 6 expression in the serum were observed $3 \mathrm{~h}$ after high-dose $\mathrm{K} 62$ and $\Delta \mathrm{K}$ inoculation, the IL-10 levels after inoculation with $\mathrm{K} 62$ and the $\Delta \mathrm{K} 1$ mutant were much lower at day 1 and thereafter (similar to the levels for pure K2 LPS), indicating that TNF- $\alpha$ had been downregulated. All of the mice inoculated with K62 and $\Delta \mathrm{K} 1$ survived to day 14 .

Neutrophil influx into infection sites is an early immune response. Several C-X-C chemokines, including IL-8, KC (CXCL1), MIP-2 (CXCL2) and GRO $\gamma$, possess potent neutrophil chemotactic activities. ${ }^{35}$ Furthermore, MIP-2 could be produced by the infected hepatocytes, thereby regulating neutrophil infiltration and microabscess formation. ${ }^{36}$ In this study, the markers MIP-2 and KC were detected in liver tissue at all time points, increasing gradually and peaking at day 3 in both liver and serum samples, especially in the K1 and K2 groups. These findings suggest that a massive neutrophil infiltration may lead to abscess formation in infected patients.

The present study demonstrated that the sequential, innate immunological and pathological changes caused by the phagocytic-resistant, $\operatorname{rmp} A$ and aerobactin-carrying K. pneumoniae serotypes $\mathrm{K} 1 / \mathrm{K} 2$ matched the severity of disease progression. These findings illustrate the critical role that phagocytic resistance plays against innate immunological defense mechanisms and also its contribution to the development of liver abscess.

\section{ACKNOWLEDGEMENTS}

We thank Professor Stephen Phillips (Division of Infection and Immunity, University of Glasgow, Glasgow, United Kingdom) for his critical reading of the manuscript. This work was supported by grants from the National Science Council of Taiwan (NSC 91-2314-B-075-027, NSC 93-2314-B-016-018 and NSC 94-2314-B-016-004).

\section{DISCLOSURE/CONFLICT OF INTEREST}

The authors declare no conflict of interest.

1. Fung CP, Chang FY, Lee SC, et al. A global emerging disease of Klebsiella pneumoniae liver abscess: is serotype $\mathrm{K} 1$ an important factor for complicated endophthalmitis? Gut 2002;50:420-424.

2. Yeoh KG, Yap I, Wong ST, et al. Tropical liver abscess. Postgrad Med J 1997;73:89-92.

3. Wiwanitkit V, Suwansaksri N, Suwansaksri J. Causative agents of liver abscess in those with liver cirrhosis: a 10-year case review of hospitalized patients in Thailand. Ann Trop Med Parasitol 2002;96: 513-516.

4. Okano $\mathrm{H}$, Shiraki $\mathrm{K}$, Inoue $\mathrm{H}$, et al. Clinicopathological analysis of liver abscess in Japan. Int J Mol Med 2002;10:627-630.

5. Nadasy KA, Domiati-Saad R, Tribble MA. Invasive Klebsiella pneumoniae syndrome in North America. Clin Infect Dis 2007;45:e25-e28. 
6. Lederman ER, Crum NF. Pyogenic liver abscess with a focus on Klebsiella pneumoniae as a primary pathogen: an emerging disease with unique clinical characteristics. Am J Gastroenterol 2005;100: 322-331.

7. Rahimian J, Wilson $\mathrm{T}$, Oram V, et al. Pyogenic liver abscess: recent trends in etiology and mortality. Clin Infect Dis 2004;39:1654-1659.

8. Chung DR, Lee SS, Lee HR, et al. Emerging invasive liver abscess caused by K1 serotype Klebsiella pneumoniae in Korea. J Infect 2007;54:578-583.

9. Fung CP, Siu LK. Virulence of Klebsiella pneumoniae serotype K2 should not be underestimated in $K$. pneumoniae liver abscess. Clin Infect Dis 2007;45:1530-1531.

10. Yeh KM, Kurup A, Siu LK, et al. Capsular serotype K1 or K2, rather than magA and rmpA, is a major virulence determinant for Klebsiella pneumoniae liver abscess in Singapore and Taiwan. J Clin Microbiol 2007;45:466-471.

11. Fang CT, Chuang YP, Shun CT, et al. A novel virulence gene in Klebsiella pneumoniae strains causing primary liver abscess and septic metastatic complications. J Exp Med 2004;199:697-705.

12. Yu WL, Ko WC, Cheng KC, et al. Association between rmpA and magA genes and clinical syndromes caused by Klebsiella pneumoniae in Taiwan. Clin Infect Dis 2006;42:1351-1358.

13. Yu WL, Ko WC, Cheng KC, et al. Comparison of prevalence of virulence factors for Klebsiella pneumoniae liver abscesses between isolates with capsular K1/K2 and non-K1/K2 serotypes. Diagn Microbiol Infect Dis 2008:62:1-6.

14. Yu VL, Hansen DS, Ko WC, et al. Virulence characteristics of Klebsiella and clinical manifestations of $K$. pneumoniae bloodstream infections. Emerg Infect Dis 2007;13:986-993.

15. Nassif X, Sansonetti PJ. Correlation of the virulence of Klebsiella pneumoniae $\mathrm{K} 1$ and $\mathrm{K} 2$ with the presence of a plasmid encoding aerobactin. Infect Immun 1986;54:603-608.

16. Nassif X, Fournier JM, Arondel J, et al. Mucoid phenotype of Klebsiella pneumoniae is a plasmid-encoded virulence factor. Infect Immun 1989;57:546-552.

17. Yeh $\mathrm{KM}$, Lin $\mathrm{JC}$, Yin FY, et al. Revisiting the importance of virulence determinant magA and its surrounding genes in Klebsiella pneumoniae causing pyogenic liver abscesses: exact role in serotype K1 capsule formation. J Infect Dis 2010;201:1259-1267.

18. Yeh $\mathrm{KM}$, Chang FY, Fung CP, et al. magA is not a specific virulence gene for Klebsiella pneumoniae strains causing liver abscess but is part of the capsular polysaccharide gene cluster of $K$. pneumoniae serotype K1. J Med Microbiol 2006;55:803-804.

19. Itou T, Collins LV, Thoren FB, et al. Changes in activation states of murine polymorphonuclear leukocytes (PMN) during inflammation: a comparison of bone marrow and peritoneal exudate PMN. Clin Vaccine Immunol 2006;13:575-583.

20. Lin JC, Chang FY, Fung CP, et al. High prevalence of phagocyticresistant capsular serotypes of Klebsiella pneumoniae in liver abscess. Microbes Infect 2004;6:1191-1198.
21. Curek GD, Cort A, Yucel G, et al. Effect of astaxanthin on hepatocellular injury following ischemia/reperfusion. Toxicology 2010;267: 147-153.

22. Liu YC, Cheng DL, Lin CL. Klebsiella pneumoniae liver abscess associated with septic endophthalmitis. Arch Intern Med 1986;146: 1913-1916.

23. Chang FY, Chou MY. Comparison of pyogenic liver abscesses caused by Klebsiella pneumoniae and non-K. pneumoniae pathogens. J Formos Med Assoc 1995;94:232-237.

24. Tang HL, Chiang MK, Liou WJ, et al. Correlation between Klebsiella pneumoniae carrying pLVPK-derived loci and abscess formation. Eur $J$ Clin Microbiol Infect Dis 2010;29:689-698.

25. Mizuta K, Ohta M, Mori M, et al. Virulence for mice of Klebsiella strains belonging to the $\mathrm{O} 1$ group: relationship to their capsular $(\mathrm{K})$ types. Infect Immun 1983;40:56-61.

26. Athamna A, Ofek I, Keisari $\mathrm{Y}$, et al. Lectinophagocytosis of encapsulated Klebsiella pneumoniae mediated by surface lectins of guinea pig alveolar macrophages and human monocyte-derived macrophages. Infect Immun 1991;59:1673-1682.

27. Keisari $Y$, Kabha K, Nissimov L, et al. Phagocyte-bacteria interactions. Adv Dent Res 1997r;11:43-49.

28. $\mathrm{Wu} \mathrm{JH}, \mathrm{Wu} A M$, Tsai $\mathrm{CG}$, et al. Contribution of fucose-containing capsules in Klebsiella pneumoniae to bacterial virulence in mice. Exp Biol Med (Maywood) 2008;233:64-70.

29. Nakajima $\mathrm{Y}$, Momotani $\mathrm{E}$, Takahashi $\mathrm{H}$, et al. Endogenous tumor necrosis factor (TNF) production and modification of pathological lesions in experimental Escherichia coli endotoxemia of piglets. Vet Immunol Immunopathol 1995;45:45-54.

30. Nakajima Y, Mikami O, Yoshioka M, et al. Involvement of apoptosis in the endotoxemic lesions of the liver and kidneys of piglets. J Vet Med Sci 2000;62:621-626.

31. Teoh N, Field J, Farrell G. Interleukin-6 is a key mediator of the hepatoprotective and pro-proliferative effects of ischaemic preconditioning in mice. J Hepatol 2006;45:20-27.

32. Armstrong $L$, Millar $A B$. Relative production of tumour necrosis factor alpha and interleukin 10 in adult respiratory distress syndrome. Thorax 1997;52:442-446.

33. Charavaryamath C, Janardhan KS, Caldwell $\mathrm{S}$, et al. Pulmonary intravascular monocytes/macrophages in a rat model of sepsis. Anat Rec A Discov Mol Cell Evol Biol 2006;288:1259-1271.

34. Gogos CA, Drosou E, Bassaris HP, et al. Pro- versus anti-inflammatory cytokine profile in patients with severe sepsis: a marker for prognosis and future therapeutic options. J Infect Dis 2000;181:176-180.

35. Bozic CR, Gerard NP, von Uexkull-Guldenband C, et al. The murine interleukin 8 type $B$ receptor homologue and its ligands. Expression and biological characterization. J Biol Chem 1994;269:29355-29358.

36. Ebe $\mathrm{Y}$, Hasegawa $\mathrm{G}$, Takatsuka $\mathrm{H}$, et al. The role of Kupffer cells and regulation of neutrophil migration into the liver by macrophage inflammatory protein-2 in primary listeriosis in mice. Pathol Int 1999;49:519-532. 